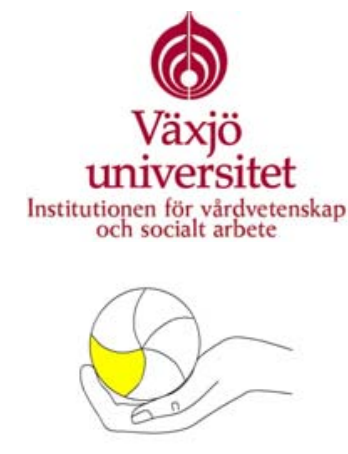

Kunskapscentrum för Livsvărldsdidaktik

\title{
Developing a didactic method that emphasizes lifeworld as a basis for learning
}

Margaretha Ekebergh Växjö Universitet 35195 Växjö

Tel: 0470/70 8301

Mobilnr. 0702866040

margaretha.ekebergh@vxu.se 


\section{Developing a didactic method that emphasizes lifeworld as a basis for learning}

\section{INTRODUCTION}

The learning process for nursing students is characterised by the encounter between the student's own lifeworld and scientific knowledge in theory and in practice. The aim is for the students to be able to gain sufficient knowledge so that they can understand the patient and the care context where the world of the patient is in focus. Didactics is needed in order to provide support for this meeting and create the conditions for a reflective process that strengthens the integration between the lifeworld and theoretical and practical knowledge. The purpose of the present project was to develop a supervision model which is able to meet these demands. Furthermore, we intended to develop a form of examination for the clinical training that makes it possible to assess the development of the student's understanding of the patient's own situation and needs. This project has been financially supported by the Council for the Renewal of Higher Education in Sweden.

\section{Rationale for change}

Students in the undergraduate Nursing programme and advanced Nursing programmes gain professional knowledge that is based on the caring science the programme's major subject. The caring sciences exist in both theory and in practice, which means that there are two fields of knowledge from which knowledge about caring can be acquired. In the theoretical field of caring science we work with abstract and general descriptions of caring, which are not the same as the often more complex reality of practical caring. Students often have difficulties in utilising theories in real life experiences of various nursing contexts. They assimilate the theoretical meanings of the major terms in caring science but have difficulty in converting them or using them as tools when encountering patients in clinical practice. Students, for example, experience a noticeable difference between theory and reality when attempting to understand the patient's everyday life. This understanding is in fact the foundation for creating a caring relationship and for meeting the patient's needs. This problem in the process of learning is probably intensified by the fact that the patient's perspective is often diffused or non-existent in the practical field. A further complication is that the supervision the students receive in their clinical practice is seldom integrated with caring science but is more an empty technology that lacks a caring science perspective. Thus the students experience a gulf between the substance of the subject of caring science and caring in both the practical field as well as in the didactical sense. Attempts to alleviate this problem have previously been made by, on the one hand developing the theoretical content of the study programme and on the other by developing the contents of clinical training. However, this has appeared to increase the gulf between theory and practice. In order to find a solution for this problematical situation in the nursing students' learning process, a didactic method is needed so that the abstract caring science knowledge can encounter the lived reality of the practical field so that the students can acquire caring science knowledge that is optimal for use in a caring context. If the conditions for this encounter are not created in the students' learning process they will often, without reflection, assimilate the medical perspective. The latter is predominant in the practical field but does not take into account the patients' experiences. A relevant issue in relation to this is the development of forms of examination. Students should be examined in such a way so that an assessment can be made of how well the students have been able to integrate caring science in theory with practical experiences from the clinical training. When examining, the clinical training assessment can be made of the knowledge as expressed in different forms; in language (thoughts and feelings), in approach to patients and in actions. However, examinations of clinical training are not conducted in such a way as to clarify this integration; they are often focused on the performance of specific tasks. 


\section{Review of relevant research publication}

In a research review of the comprehensive area of theory-practice relationship and reflection, themes such as reflection as a support for learning, collaboration between academia and clinical practice appear, linking theory with practice and models for supervision and learning. The present review covers a selection of research publications. O'Callaghan (2005), Tveiten \& Severinsson (2006) and Avis \& Freshwater (2006) show the importance of reflection to develop a solid foundation for knowledge in the nursing area, which includes personal learning and development. Crowe \& O’Malley (2006) enhance this statement by developing teaching critical reflection skills for advanced nursing students. However, Stein (2005) highlights the issue of teaching critical reflection and with a strong critical approach to research findings in this area; he comes to the conclusion that the use of critical reflection has had more success in the classroom, than when doing clinical practice. Collage work as a medium for guided reflection has been studied by Williams (2000), whose findings show that this medium helps students to put words on emotions and personal frameworks of values involved in the learning process in clinical practice. An example of research, with the aim to develop a model for nursing students in clinical practice, is Häggman-Laitila et al. (2007). The researchers show that the model could unify the notions of all parties concerned of the prerequisites, content and influence of clinical supervision. Another study, which investigated a general model for acquiring learning skills (Spector-Levy et al 2006), shows a positive result with developed communication skills among the students. There are also studies of using reflection models based on theoretical concepts from a nursing theory, for example Parse's Theory of Human becoming $(1981,1998)$ and the adherent teaching-learning process. The purpose of these studies is to illustrate how nursing students develop an understanding of the meanings of theoretical concepts, and interwoven them with practice, with the purpose to reach a deeper understanding for caring (Mitchell, 2002). In one of these studies the focus was on learning through the patients and the lived knowledge, to deepen the meaning of caring concepts (Milton, 2003). A reflective journaling process was also developed from this theory based perspective, which provided a self-journaling process that enhanced personal growth (Letcher \& Russell Yancey, 2004). Collaboration between academia and clinical practice, to bridge the theory-practice gap, has a certain interest within this research area. Examples of such studies are when lecturers and clinical supervisor are working together in teaching and supervision sessions (Davies, et al, 1999), providing continuing training for staff nurses (Mayer, 2000), and when increasing the nursing training with an internship (Perry, 2000). All these projects show findings that might improve the possibilities for students to link theory with practice. Gallagher (2003) provides an alternative perspective, which considers learning as an inseparable and continuously evolving discourse between thoughts, experiences and actions. The gap is artificial; the learning process is not able to be divided, instead it is a holistic process, it is an embodied learning. In relation to this perspective the importance of student's experiences arise. To facilitate the theory-practice connection one study focused on starting the learning process in the students own experiences (van't Hooft, 2005). Furthermore, experiential learning has been developed and studied in nursing training (Welch, et al, 2001) and Melby (2001) shows that experiential learning strengthens analytical skills and a more holistic approach to care. Reflection is seen as an invaluable part of experiential learning and according to these findings, encouragement of reflection helps students to identify what they have learnt. Findings from a nursing educational project with the aim to develop a reflective supervision with educational drama showed that the three mainstays of supervision are the student's lifeworld, caring science knowledge and the method of educational drama for supervision. All three aspects are essential in the supervision but with particular emphasis on the lifeworld (Ekebergh, Lepp \& Dahlberg, 2004). 
A conclusion of the research review is that there are comprehensive variations of research within the area of linking theory with practice and reflection. The review shows however, that the complexity in this area calls for more research to find the core of learning in a professional training as nursing education. An obvious lack in previous research is that there is very little attention to the student's lifeworld in the learning process, and also the importance of the substance of learning and its scientific base for developing learning support. Therefore the present project takes a starting point in lifeworld and reflection in connection with theory and practice of caring science to combine all these aspects in developing a learning model.

\section{Questions}

The follow questions were addressed in the project:

- Which didactics can, in a fruitful way, support the integration of theory and practice with the student's lifeworld?

- How can we apply reflection to link theory with practice?

- How can the supervisor meet the student's lifeworld?

- How should theory be applied to meet the experience-based knowledge in practice?

\section{Theoretical foundation for the project}

The idea of the project is grounded in a lifeworld approach, which emphasizes the learner's learning attitude, experiences and embodied understanding. The platform for learning and reflection is the lifeworld. The latter, according to Husserl's (1973) philosophy, relates to the natural attitude, which involves a type of approach to our everyday activities (Dahlberg et al., 2001). The natural attitude characterizes activity in which humans are completely directed towards, immersed in, and absorbed by the activity, or the being, of the moment. In everyday activities humans do not consciously analyse what they are experiencing, but presuppose what they are absorbed by as existing in the way they perceived it. Consequently a person's natural attitude is basically unreflective. All meaning has its origin in the lifeworld and it is the prerequisite for all cultivation of knowledge. The lifeworld can, according to Husserl (1970, 1998) be examined and conceptualized through reflection. Through reflection, phenomena of the world will be brought to awareness and with that made available for analysis, instead of being taken for granted. In this way phenomena in the lifeworld might be conceptualised and articulated, which is the ground for the learning process and starting point for this project.

A person and the world are constituted by each other and form a unity, which cannot be divided. To live means to be in a historical, cultural and social context, this together with the person creates a unity (Gadamer, 1989). Through reflection we work with existing meanings, value sets and approaches. We discover and reconsider new versions of our experiences and our attitudes. The reflective experiences will be structured in consciousness, but what and how they are structured depends on earlier experiences. From this perspective it is obvious that the individual learning starts in earlier experiences, which is the base for the individual understanding. Accordingly, the lifeworld is the platform for learning and through reflection the learning process starts and is continuously ongoing. Consequently, learning must always be understood in relation to the individual and her/his experiences added to the learning. According to this we adopt a lifeworld perspective that we have strived to maintain during the implementation process.

\section{METHOD}

The starting point of the project was to address the existing gap between the theoretical and practical parts in nursing training (Ekebergh, 2001). This dilemma also appears in advanced nursing programmes. Students experience that the theoretical knowledge they acquire is difficult to convert into a practical context when meeting a patient. This problem is 
particularly noticeable when the student is going to develop an approach to patients that emphasises the patient and his/her experiences as the foundation for all caring.

During clinical studies the students should use the theoretical knowledge as a tool, to develop an understanding for the patient's world. The context of this study makes the "theory-practice problem" visible and the demand of a unique didactic method becomes obvious. This method must have the capacity to, support the students in their encounters with the patient's lifeworld, to receive the patient's narrative, and start the student's reflection process, when the patient's lived narrative meets the caring science concepts. According to this idea, four principles create the foundation for the development of the method.

- integration of caring science in theory with practical nursing experiences is achieved by conscious and systematic reflection

- caring science in theory comes alive through patients' narratives that are based on lived experiences

- the starting point for reflection and learning is in the student's lifeworld

- reflection can be further stimulated by drama activities

\section{Students}

Students from the second and third year of nursing training participated in the project. The clinical studies cover 10 weeks. For the second year students these 10 weeks are divided into 5 weeks in psychiatric wards and 5 weeks in somatic care wards. The third year students have placements in community health care (5 weeks) and in hospital care (5 weeks). The amount of students has gradually increased during the project's two years. The first term four student groups with 8 in each group participate and during the last term of the project 99 students took part in the project's supervision model.

In the advanced nursing programme, specialist training for pre-hospital care, one group of 8 students took part the first term and the last term a group of 11 students. In the other specialist programmes within emergency care and psychiatric care students took part in a modified version of the project and these are therefore not shown in the table below.

\section{Overview of student participation}

\begin{tabular}{|l|l|}
\hline \multicolumn{2}{|c|}{2005} \\
\hline $\begin{array}{l}\text { Spring: } \\
\text { Undergraduate Nursing Program Second year }\end{array}$ \\
$0 \quad 4$ groups, 33 students
\end{tabular}

\begin{tabular}{|c|c|}
\hline \multicolumn{2}{|c|}{2006} \\
\hline $\begin{array}{l}\text { Spring: } \\
\text { Undergraduate Nursing Program Second year } \\
0 \quad 5 \text { groups, } 42 \text { students } \\
\end{array}$ & $\begin{array}{c}\text { Advanced Nursing program } \\
2 \text { groups, } 11 \text { students } \\
\end{array}$ \\
\hline $\begin{array}{l}\text { Undergraduate Nursing Program Third year } \\
0 \quad 6 \text { groups, } 54 \text { students } \\
\end{array}$ & \\
\hline $\begin{array}{l}\text { Autumn: } \\
\text { Undergraduate Nursing Program Second year } \\
\text { o } 5 \text { groups, } 45 \text { students }\end{array}$ & \\
\hline $\begin{array}{l}\text { Undergraduate Nursing Program Third year } \\
\text { o } 6 \text { groups, } 54 \text { students }\end{array}$ & \\
\hline
\end{tabular}


The students in the nursing programme are mostly a heterogeneous group, according to age and background. Some students go directly from upper secondary school to nursing training and others have been working for a time, mostly within healthcare. A majority of students are female, even if the amount of male students has increased during the last years. The training is for three years and include a professional degree as well as an academic; a bachelor degree. The major is caring science, which is focused on the patient and its world in relation to wellbeing, suffering and caring. Other subjects in the training are first of all medical science, and subjects within social and behavioural science. During the clinical studies the students should be able to integrate and apply knowledge from these sources, according to the patient perspective.

The students in the advanced nursing programmes have a nursing training and professional experiences within nursing and caring when they start this specialized training. The training is for one year; the first term has mostly theoretical contents and the second consists of clinical practice with some theoretical parts. The major in these programmes is caring science, with emphasis on professional knowledge.

\section{Innovation}

The project was named REDI (= Reflection and Didactics) and the purpose was two-fold. The students should be able to use the theoretical knowledge in a better way and be able to combine it with experiences in practice, in order to discover patterns in the caring context and thereby reach understanding of and insight in the patient's needs and situation. Furthermore the students should be examined in an adequate way, according to the demand of integrating theoretical knowledge and practice experiences. In other words, it is necessary to explicitly estimate the students' ability to understand and reach insight in addition to the caring actions; i.e. to make the student's caring science reflection visible in the assessment.

The didactic challenge entails creating a learning milieu that recognizes both the patient's lifeworld and that of the student. If the didactic method was to be successful in the learning process it must treat the student's lifeworld as the platform for learning. From that statement we developed a method, REDI supervision, for reflective learning, based in caring science and built around the following components:

- Student-groups with 6 to 8 students in each group were formed for caring science reflective learning in the practical nursing field during the second and third year in the undergraduate and advanced programmes in nursing.

- The groups were lead by a teacher (= theoretical caring science perspective) and a nurse (= practical caring science perspective).

- The groups gathered every second week.

- The students brought written narratives with them to the reflection group and these narratives constituted the basis for the reflective work.

- The reflective work was carried out with the help of caring science theory and with elements of creative didactics in the form of drama activities.

- The results of the students' learning processes were assessed in an examination in a clinical context. These assessments were adjusted to the specific aims for each programme and level of the programme.

Continuously during the project's execution, evaluations have been carried out with the purpose to support the development of the supervision model. These evaluations have consisted of questionnaires, interviews with students and supervisors in groups and individually, written narratives from students and tape recordings from parts of the supervision sessions (see page 10). 


\section{Training for supervisors}

All teachers and nurses in the project were trained during a specialized 5 week course, Lifeworld didactics. The central content of this course was how supervision, based in lifeworld theory, can support reflection and learning. Furthermore, the content was constructed around the substance of caring science supervision and its applications. The course started with a theoretical part, followed by a practical, where the participants were able to practice different methods of caring science supervision and also become familiar to work in pairs in the supervision session. This training was carried out three times, and 22 nurses and 18 teachers participated.

\section{Implementation of the two years}

On a clear epistemological base (Lifeworld theory) and carefully planed principles for method development, the project could have had a quick start in the first term. A project group was formed, consisting of faculties, students and professionals. The students maintained a good connection between the project group and the students in the training programmes. The collaboration and information to hospitals and community care were of crucial importance, as the supervision model was to be applied in the clinical practice, during the students' clinical studies. Contacts were established with key-persons in theses contexts. Information programmes were carried out in the practical field, in both hospitals and community and information handouts were produced. The implementation of this work was systematic and well-planned, which was the central strength of the execution of the project. A decision was made to also include the advanced programme in the project, which seemed to be a good choice. That gave us possibilities to evaluate the model in a broader perspective.

During the first term 5 teachers and 5 nurses were trained in the REDI supervision model. They supervised student groups during the latter part of the term and examined them in the clinical examination. This extension proved to be appropriate for the first term. We had a good opportunity to follow and evaluate the supervision and learning process in an adequate way and could find suitable solutions for problems and questions that appeared. It was obvious that a flexible approach was necessary to find realistic solutions for the two programmes. The project group formed a very close relationship with the teachers and nurses that worked with the REDI supervision. The supervision process and the students' learning could be followed in each student group with a simple questionnaire. After the supervision period, interviews were made with students and supervisors. The results of these evaluations at the end of the first term led to the development of the model and indicated the need of increased support to the supervisors. These evaluations followed each term throughout the two years, in addition with other evaluation forms (se page 8).

The second term we were ready to increase the project. Twenty teachers and nurses were trained in the REDI supervision model. With such a large amount of trained supervisors, the supervision model could be implemented in the educational programmes faster and to a greater extent. The vulnerability of the model could be reduced if we had more trained supervisors who had the competence to use the supervision model. The amount of student groups also increased in both programmes and also the amount of supervision sessions during a period of clinical studies.

In the project's third term it was time to introduce the model in the community care for students in the third year of training in the undergraduate programme. The information had started at the beginning of the project for both students and professionals in the community care fields, but some practical arrangement were needed as the students' placements were spread in a large geographic area and therefore it was important to find where it was best to have the supervision session and also when. We found that this must be adjusted to the caring 
organisation and the students' situation in the actual context, which meant that it could vary among different districts. The clinical examination was developed to suit the educational goals on the third year level in the undergraduate programme.

The second year the project increased at an appropriate pace. Some more supervisors were trained and the amount of supervisions groups increased to include, at the end of the project, all students in clinical studies in the undergraduate programme. In the advanced programme the project increased to include student groups from different specialities, such as ambulance, anaesthesia and intensive care. In these contexts the model had to be applied in different ways but on the principles for the model development.

\section{Data collection}

Data has continuously been collected using different methods. Group interviews and individual interviews with students and supervisors have been carried out with a lifeworld approach. Furthermore, the students have filled out a questionnaire after each supervision session. A large amount of patient narratives that the students brought to the supervision sessions have also been collected for analysis. In addition to this, some "closing rounds" in the supervision sessions, which is the event for each student to verbalize the subjective experiences of the actual supervision session and what they have learnt, were recorded to give a picture of the students' experiences.

The interviews focused on experiences of the supervision model's importance for learning and integration of theory and practice and the understanding the patient's world. From the student's perspective the task was to grasp their learning and reflection, i.e. how they think and feel regarding their understanding of the patient's situation and needs. Furthermore, their quotations about the caring relationship were of interest. Their experiences of what they had learnt and how they thought about their personal growth was also of importance.

The interviews with the teachers and nurses, i.e. the supervisors, were centred on their experiences of using the supervision model for integrating caring science theory with practice. Their views on meeting the students in their lifeworld and creating a learning atmosphere and how they experienced the use of different strategies and methods strengthened the reflection.

\section{Overview of the data collection}

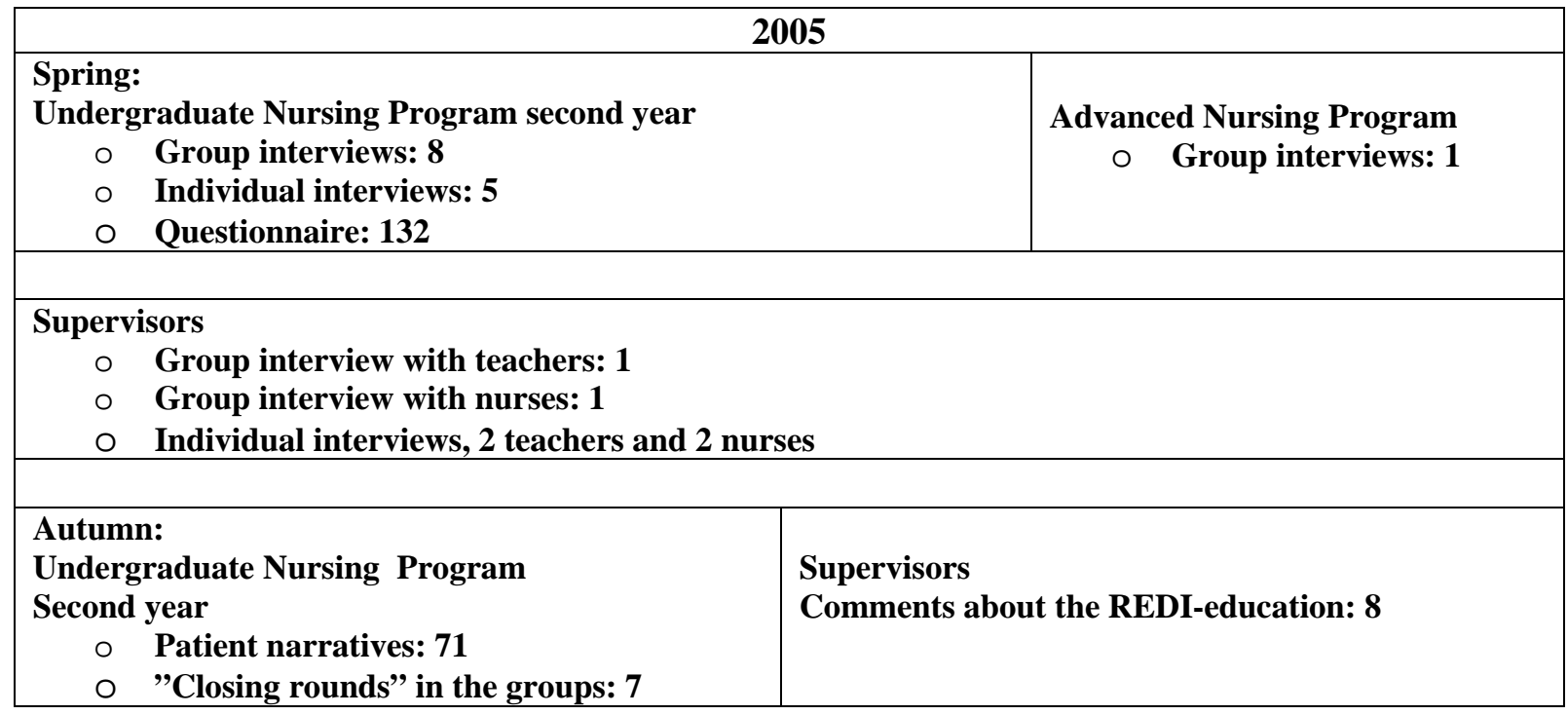




\begin{tabular}{|c|c|}
\hline \multicolumn{2}{|c|}{2006} \\
\hline $\begin{array}{l}\text { Spring } \\
\text { Undergraduate Nursing Program Second year } \\
\quad \text { o } \quad \text { Group interviews: } 6 \\
0 \quad \text { Questionnaire: } 168\end{array}$ & $\begin{array}{l}\text { Advanced Nursing Program } \\
0 \text { Questionnaire with open questions: } 5\end{array}$ \\
\hline $\begin{array}{c}\text { Undergraduate Nursing Program Third year } \\
\text { o Patient narratives: } 30 \\
0 \text { "Closing rounds" in the groups: } 8 \\
\end{array}$ & \\
\hline $\begin{array}{l}\text { Autumn } \\
\text { Undergraduate Nursing Program Second year } \\
\qquad \begin{array}{l}\text { Group interviews: } 5 \\
0\end{array} \\
\text { Questionnaire: } 180\end{array}$ & $\begin{array}{l}\text { Supervisors } \\
\text { o } \\
\text { o } \\
\text { Group interviews with teachers: } 3 \\
\text { Group interviews with nurses: } 3\end{array}$ \\
\hline $\begin{array}{cl}\text { Undergraduate Nursing Program Third year } \\
\begin{array}{cl}\text { o } & \text { Patient narratives: } 48 \\
\text { o } & \text { Group interviews: } 6 \\
\text { o } & \text { Individual interviews: } 3 \\
\text { o } & \text { Questionnaire: } 216\end{array}\end{array}$ & \\
\hline
\end{tabular}

Data from interviews, narratives and tape recordings from supervision sessions have been analyzed according to definitions, with the goal to describe the essential meaning of the supervision by the REDI model, based on students' and supervisors' experiences. In this paper the findings from student interviews, supervisor interviews and the student narratives are presented in a condense way with focus on the essential outcomes.

\section{RESULTS}

Findings from the student interviews in the nursing programme show that REDI supervision, as a learning support, implies symbolically a confrontation between the student's lifeworld, the caring science and the patient's lived world. With this confrontation a vital learning process begins, which engages and creates tension in the student's world. Prejudices are challenged and the power of curiosity constitutes the basis for discovering the patient's world. The students are forced to step out from their natural attitude, i.e. their presumptions, and with reflection "see the patient". This is stimulated with help of the caring science concepts, which open horizons for new understanding of the patient and his/her needs.

The starting point for learning is the encounter with the patient and his/her suffering. To receive the patient's narrative is, according to the students', a reverent act. They show great respect for it as conversations with patients create insecurity and fear. The subjective experience is insufficient to handle this insecurity and if the students do not get support to master this encounter with patients, they escape the proximity to the patient and instead observe the caring event at a distance.

The analysis of the patient's narrative takes a powerful grasp of the student's whole world which triggers an embodied learning. The lived body, as a bearer of thoughts, feelings, experiences and bodily expressions is activated in the learning process. The feelings receive dignity in this embodied learning and the subjective experience of the caring relationship. In this way the learning involves the student in a profound sense.

The reflection and analysis of the patient's narrative, with the help of caring science concepts, constitute a vital movement in the learning process between the entirety and its parts. The challenge for the students is to see the entirety in relation to its parts and the parts in relation to its entirety. A new understanding might occur that gradually settles in the body as an embodied understanding. If the movement fails to appear the learning might become fragmental and shallow. 
It is obvious, according to the findings from the students' interviews, that a good learning support requires an open approach to the students' lifeworld. The students' need of learning is expected to have priority in the supervision, and the prerequisite for that is the interaction between the patient's lifeworld, which is in focus in the supervision session, and the student's lifeworld. The group plays an important role to create free scope for each student's learning and personal growth.

The following themes are therefore central regarding the REDI supervision as a learning support for the students:

- Focus on the patient

- The meeting between the patient's lifeworld and the caring science

- The patient's lifeworld is confronted with the student's lifeworld

- The potential of reflection in learning

- The embodied learning

- The possibilities of learning support

Findings from the interviews with students in the specialist training for pre-hospital care show that the reflective supervision involves a perspective characterized by a strong faith in the importance of the narrative for learning. With the tangible and animated patient narrative, the basis for the supervision, a lively activity in the learning process is started. This exposes prejudices and values and changes views which in turn change the understanding of the patient's situation and the care. This new view opens up a broader and more developed understanding of the patient's world, but is narrowed when focusing on problems and problem solving. This is supported by a methodological focus during supervision, which in its turn makes reflection difficult.

Reflection appears in the meeting between patient narrative, student experience and praxis related knowledge. The caring science plays a subordinate role in reflection as it is experienced as unnecessary and lacks meaning for the care of the patients.

The aim for the students is to develop good skills in caring, where theoretical terminology does not fit in. When the caring science carries little weight in the supervision, it is excluded from the learning process and thereby the gap between caring science and caring increases. There is, however, a desire to transform caring science into practical actions, which is seen as optimal in caring. This desire is, however, not fulfilled in the supervision.

The weak support in the supervision for understanding caring science knowledge and combining it with caring practice creates gaps in the students' learning, which in turn creates dissatisfaction with them.

The following themes are therefore central regarding the REDI supervision as a learning support for the specialist students:

- The narrative's power in the supervision

- Problem and method focus

- The strength of good skills

- The gap between the caring science and caring

- Unreflected relation to caring science

Findings from the supervisors' interviews show that the learning strength in supervision is created when "two worlds" meet in an attuned unity. This forms a solid basis for combining theory and practice. The supervision unity is characterized by mutuality and respect of each other's knowledge. This unity is, however, vulnerable and requires proximity and openness for the two worlds in order to create a safe co-operation. The co-operation requires courage to 
present and represent the knowledge each supervisor has in order to create role models for the students. These role models are in turn deepened with reflection.

Reflection in the supervision takes place at the same time in supervisors and students and finds nourishment in feelings that are discovered and articulated. The purpose of reflection is to confuse, disarrange and thereby awaken itself. By visualizing ways for thoughts and reflection, patterns of thinking become clear to the students and they can thereby experience the possibilities of reflection.

The challenge for the supervision is to meet the student in her/his learning. It is essential that the supervisors listen, see and feel in order to notice the student's needs for support. It is a matter of a genuine interest with an emotional commitment for the student and her/his learning. The goal is to have an open and flexible attitude, with balance as a motto; a balance between being flexible and challenging, and between being demanding and permissive.

The aim of the supervision is to create a learning and joyful environment where students become interested in learning more. The scientific terminology is woven into the patient's narrative which is the foundation for the learning environment. By methodologically working the caring science knowledge, the patient's narrative and the practice knowledge, the purpose is to deepen the student's understanding of the patient's situation. The overriding obstacle for the student's learning can be traced back to both students and supervisors. However, prominent obstacles are related to difficulties for supervisors in approaching the student's learning profile as well as problems with clarifying the patient perspective in relation to care and lacking a competence in caring science.

The following themes are therefore central regarding the REDI supervision as a learning support for the supervisors:

- Two fold supervision

- Reflection as learning support

- Combination of caring science with patient narrative

- The student as learning subject

- The learning environment of supervision

The patient narratives differ in width, depth and perspective. They are referred to as narratives, case reports, patient cases or just cases. Some are very short and consist of information from the medical casebook or from VIPS documentation; others are detailed about the patient's situation and includes questions and attempts of reflective reasoning. There are patient narratives that include an analysis that result in identifying central phenomena in the narrative. Some narratives relate explicitly to caring science terminology, for example suffering and care relation. The narratives have, with a few exceptions, focus in the patient's perspective, even if they do not always take their starting point in the dialogue with the patients.

The themes that appear in the narratives are:

- Standing on the side and observing with a patient perspective

- Proximity to the patient's world

- Meaning of hope

- Characteristics of the care context

- Problem orientation

- Emergence of care suffering in the care relationship 


\section{DISCUSSION}

The REDI project has in general had a positive effect on the students' learning. The students experience that with the help of this didactic method they have for example achieved a better understanding of the patient and have had good use of the theoretical caring science in this. They have also learnt to reflect more systematically and the examination has then become more real as it was carried out in a clinical context. There are some necessary prerequisites for this positive experience though, which can be summarized as acknowledging the student's lifeworld in the supervision.

The supervisors experience the didactics as more creative and stimulating than working traditionally. The co-operation in the supervision is challenging but enriching and developing for both perspectives when the co-operation worked in a positive way. In the discussion, difficulties and weaknesses are presented initially, thereafter follows questions regarding the process of establishing the method and the implementation of the project and finally what conclusions can be drawn and how to continue.

\section{Balancing the student's lifeworld with the patient's}

The challenge for the supervisors is to maintain a clear patient perspective in the supervision so that the students can understand and acquire that perspective, but at the same time the supervisors must be open to the students' lifeworld. A rivalry may occur between two lifeworld foci; the patients and the students. The students may need to share experiences that affect them on a personal level, i.e. their own thoughts and feelings that they associate to the narrative at hand. If the supervisors do not create a space for this, but hold on to the patient narrative, students can experience insecurity which leads to disappointment and criticism of the supervision. The ideal supervision is flexible and follows the students' need to learn about the patient's world. Good supervision takes its starting point in the student and remains in the student's experiences and feelings, and from this moves to clarify the interplay with the patient's lifeworld. It can feel safe and positive to do this in the supervision group. This feeling of security can falter if space is not given to every lifeworld.

\section{The structure of supervision takes over}

The given structure for the supervision session, which involves focus on one or two patient narratives, decides how each session is carried out. Often, one narrative takes such long time that there is no time to work on the second one, which creates disappointment among the students. The supervision sessions are not enough for everyone in the group to present a patient narrative; therefore it is important that the supervisors can balance the narrative in question with other experiences and needs that arise during the session without losing focus. The students must be allowed to associate to their own experiences and similar patient situations. If this flexibility is missing and the supervisors focus only on the patient narrative at hand, students can feel excluded in the supervision situation. The supervisors' ability to interact and complement each other has great importance for the quality of the supervision. The students can be very sensitive to how the interaction works. If one supervisor is more dominant, she/he can be perceived as more important. It is also important that the supervisors represent their individual perspective. The supervisors have during the project expressed these issues; the teachers are concerned that they become too dominant if the nurses take a more passive position and do not lift the issues of the practice in the supervision. During the course of supervision, the supervisors have become better at dealing with this, but it requires training and experience to become the perfect supervisor.

Even if the patient's narrative is the focus of the supervision situation, it should become clear to the student that it is not a matter of performing a task as adequately as possible. The narrative then appears as a task to complete in advance, before the supervision session, and it becomes an obstacle in their learning instead of a constructive support. 


\section{Caring science terminology - a forced structure}

The caring science terminology fills an important function as a tool for understanding the patient's world, but it might become limiting in the supervision. This occurs when the terminology is a method for dividing the narrative and the content-seeking aspect is dropped. The terminology becomes the focus when they are added to the narrative; which terminology fits to the narrative in question. The narrative is broken up with the help of terminology, something the students experience as chopping up the narrative and they cannot recognize the narrative as it was from the start. If there is no problematisation of the contents, and no entirety is recreated in order to create an understanding of the patient's narrative in a deeper and wider manner, the terminology looses its meaning in the learning process. Too much focus on terminology in the supervision can result in a vague and shallow learning, instead of a deepened and integrated complete understanding. The problem is that the narrative is lost in the work process, instead of receiving more attention. The entirety, i.e. the narrative, does not remain so the students cannot penetrate it, associate to experiences or talk it off. When the narrative is the focus of the method, there is no movement between the entirety and its parts in its aspiration for meaning. This results in an incomprehensible fragmentation for the students. The supervisors have an important task in being flexible to the students' process of understanding and in maintaining the movement between the entirety and its parts.

\section{Anchoring the project idea}

Anchoring the project with the students, who are the key persons for the development project, is one of the most important components for the project. It is also difficult as the students' focus and attention at a certain point in time can be directed at something else important for them in their studies. Their learning process is also very vulnerable and they need clarity and advance planning, why it can be difficult with the openness and flexibility the project requires. If the students in the project receive new, changed or too vague information, it can have negative consequences on the execution of the project. This also applies to the supervisors, and a balance between openness and flexibility is needed in relation to guidelines and rules. Furthermore, the varying experiences of development projects among the supervisors have to be taken into account. It is a difficult task that requires tactfulness, to create a safe and trusting environment in a development project at the same time as the idea is to challenge and create conditions for new thoughts. The project leaders are depending on the trust of the involved that has to be treated with care.

\section{Execution of the project}

The project was carried out gradually. This required good planning ahead. At the start of each term, the planning of the following term began. The second term, for example, was about developing the student supervision and the clinical examination so it could be carried out in municipal care, which has a different character than hospital care. Furthermore, the didactic method and examination had to be developed to respond to the progression needed in nursing training. One of our most conspicuous strengths in this respect was that we worked with an open and flexible attitude to the work process and its execution, which is a prerequisite in a development project such as this. Daring to test different possibilities in order to find the best alternative is an obvious strength. However, this requires a critical reflection process, with great sensitivity to what happens in the development process. This was made possible by a wide evaluation perspective and the project leaders' partaking in the execution of the process.

As the amount of student groups increased, and thus the number of supervisors, it became successively more difficult to maintain the project. It was difficult to make the project's basic ideas, the supervision model, to penetrate the project as a whole. At times there were weak points in the anchoring of the project with both students and supervisors. This led to both 
students and supervisors feeling insecure. It appeared that some supervisors found it difficult to meet the students in their lifeworld; instead they were very much controlled by the method and the structures for supervision. A failing here was that we did not oversee the supervisors satisfactorily, which is resource demanding but very important in order to make the supervision function satisfactorily. To function as pairs in supervision is a difficult task that requires training and competence.

The project has been evaluated continually with different methods, which has made it possible to analyze and examine it from a wide perspective. This caused a few problems, as the information on the different evaluation methods was too vague. The students felt insecure and refused for example to take part in recordings. The greatest weakness here was the supervisors' inability to motivate the evaluation method to the students and that they did not answer the students' questions. The supervisors experienced that they did not have a clear picture of the project and therefore found it difficult to take part in the process. The project leaders could establish that we had not been observant enough to the needs of the individual supervisor; some supervisors are more insecure and need more support than others.

One strong point for the execution of the project has been our pedagogical co-operation with the University of Bournemouth which has given inspiration and experiences. We have also been able to present our ongoing project at two international conferences which has provided us with more ideas and stimulated our work.

Carrying out a development project is of course associated with difficulties. What we mean have been our most prominent strengths, openness and flexibility, have also caused difficulties. The co-operation with the caring institutions has been a central part in the project as both teachers and nurses have carried out supervision. This means that many people have taken part in the project in different ways, both in the centre of the execution and in the periphery. We attempted to work in a goal-oriented manor in order to reach everyone with information, but this proved to be difficult as the caring institutions where the students carry out their practice are plentiful and it has been difficult to reach all caring staff that is in contact with the students during their clinical studies. We are for this dependant on our contact persons and the network we have established. There is, however, little experience from pedagogical development in the field of care which is why this type of work is unfamiliar to some care givers and for others it does not carry much importance in the care context.

\section{Conclusions}

There is extensive research regarding reflection and learning as well as on combining theory and practice with health care (e.g. Davies, et al, 1999; Mayer, 2000; Perry, 2000; van’t Hooft, 2001; Melby, 2001; O’Callaghan, 2005; Tveiten \& Severinsson, 2006; Avis \& Freshwater, 2006; Crowe \& O’Malley 2006, Welch, et al, 2001), but the REDI project's addition to the development of knowledge is mainly:

- If a didactic model is to become successful, it has to take its starting point in the student's lifeworld.

- In order to create a combination of theory and practice, the reflection should start in the patient's narrative and be the core of the supervision situation.

- The support of the combination is best carried out if a teacher and a nurse cooperate in the supervision group.

A more long-term work is needed however, if a model such as this is to become integrated in the education and receive the space it has the qualities for. We have during our two-year period come far, and will continue implementing the model and work on the weaknesses and 
failings that have been mentioned above. The co-operation with the care institutions is of great importance. Creating these networks requires tact and time, as showed above.

Based on the didactical model and the results of the project, we now take another step to develop and strengthen the students' learning in the clinical studies by establishing a learning environment at the hospital named ULVE (Development and Learning Care units), in cooperation with the Kronoberg County Council. In these units, nursing students will be supervised in care based in the patient perspective. Reflection is the hub of the combination of theory and practice to make the student understand the patient's situation and needs.

One further effect of the project is that we will use the didactical idea as a continuous learning support throughout the training, consequently not only connected to clinical studies. Thus, it is possible to take into consideration the students' lifeworld in their learning and facilitate their understanding of caring science and the nursing profession.

\section{References}

Avis, M., Freshwater, D. (2006). Evidence for practice, epistemology, and critical reflection. Nursing Philosophy, 7, (4), 216 - 224.

Callaghan, N. (2005). The use of expert practice to explore reflection. Nursing Standard, 19, (39), $41-47$.

Crowe, M. \& O’Malley, J. (2006). Teaching critical reflection skills for advanced mental health nursing practice: a deconstructive-reconstructive approach. Journal of Advanced Nursing, 56, (1), 79 - 87.

Dahlberg, K., Drew, N. \& Nyström (2001) Reflective lifeworld research. Lund: Studentlitteratur.

Davies, C., Welham, V., Glover, A., Jones, L., Murphy, F. (1999). Teaching in Practice. Nursing Standard, 13, (35), 33 - 38.

Ekebergh, M. (2001) Tillägnandet av vårdvetenskaplig kunskap - reflexionens betydelse för lärandet (The acquisition of caring science knowledge - the importance of reflection for learning). Finland, Åbo: Åbo Akademi.

Ekebergh, M., Lepp. M. \& Dahlberg, K. (2004) Reflekterande handledning med dramapedagogik - en metod för integrering av vårdvetenskap i teori med vårdpraxis. (Reflective supervision with educational drama - a method for integrating caring science in theory with caring practice, a research report). Forskningsrapport 1/2004 .Institutionen för Vårdvetenskap, Högskolan i Borås.

Gadamer, H - G. (1989) Truth and method. New York: The Crossroad Publishing Corporation.

Gallagher, P. (2003). Re-thinking the theory-practice relationship in nursing: An alternative perspective. Contemporary Nurse 14, (2), 205 - 210.

Van Hooft, M. (2005). Making Theory-Practice Connections in a Social Studies Methods Course: A Case Study. Open gates in Teacher Education, Mofet Institute. http://vcisrael.macam.ac.il/site/eng/files/print_easy.asp?propid=E4A016 
Husserl, E. (1970) Logical investigations. Volym 1 Prolegomena to pure logic. Expression and meaning. The ideal unity of the species. London: Routledge \& Kegan Paul.

Husserl, E. (1973) Experience and judgment. Evanston IL: North Western University Press.

Husserl. E. (1998) Ideas pertaining to a pure phenomenology and a phenomenological philosophy. (F. Kersten, Trans.).Dordrecht: Kluwer Academic Publ.

Häggman-Laitila, A., Eriksson, E., Meretoja, R., Sillanpää, K., Rekola, L. (2007). Nursing students in clinical practice - developing a model for clinical supervision. Nurse Education in Practice (in press).

Letcher, D. C., Yancey, N. R. (2004). Witnessing Change with Aspiring Nurses: A Human Becoming Teaching-Learning Process in Nursing Education. Nursing Science Quarterly, 17, (1), $36-41$.

Mayer, D.M. (2000). Academia and practice: Working together to provide continuing education. Dimension of Critical Care Nursing, 19, (6), 26 - 29.

Melby, V. (2001). The adrenaline rush: nursing students' experiences with the Northern Ireland Ambulance Service. Journal of Advanced Nursing, 34, (6). 727 - 736.

Milton, C. L. (2003). A Graduate Curriculum Guided by Human Becoming: Journey with the Possible. Nursing Science Quarterly, 16 (3), 214 - 218.

Mitchell, G. J. (2002). Learning to Practice the Discipline of Nursing. Nursing Science Quarterly, 15 (3). 209 - 213.

Parse, R. R. (1981). Man-living-health: A Theory of Nursing. New-York: Wiley.

Parse, R. R. (1998). The Human Becoming School of Thought: a perspective for nurses and other professionals. Thousand Oaks, Sage: Sage

Perry, I. (2000). Buildning Bridges to Clinical Practice. Kaitiaki Nursing New Zealand, 6, (1), $18-20$.

Spector-Levy, O., Bat-sheva, E., Zahava, S. (2006). Teaching communication skills in science: Tracing teacher change. Teaching and Teacher education (in press).

Stein, D. (2005). Teaching Critical Reflection. Topic Learning http://www.inspiredliving.com/business/reflection.htm

Tveiten, S. \& Severinsson, E. (2006). Communication - a core concept in client supervision by public health nurses. Journal of Nursing Management, 14, (3) 235 - 243.

Welch, L., Jeffries, P. R., Lyon, B. L., Boland, D. L., Backer, J. H. (2001). Experiential Learning - Integration Theory and Research in Practice. Nurse Educator, 26 (5), 240 - 243.

Williams, B. (2000). Collage work as a medium for guided reflection in the clinical supervision relationship. Nurse Education Today, 20, 273 - 278. 